\title{
KIEßLING, Rolf, ULLMANN, Sabine, Landjudentum im deutschen Südwesten während der Frühen Neuzeit
}

\section{Christophe Duhamelle}

\section{OpenEdition}

\section{Journals}

Édition électronique

URL : http://journals.openedition.org/ifha/1325

DOl : 10.4000/ifha.1325

ISSN : 2198-8943

Éditeur

IFRA - Institut franco-allemand (sciences historiques et sociales)

Référence électronique

Christophe Duhamelle, « KIEßLING, Rolf, ULLMANN, Sabine, Landjudentum im deutschen Südwesten während der Frühen Neuzeit », Revue de l'IFHA [En ligne], Date de recension, mis en ligne le 01 janvier 2000, consulté le 22 septembre 2020. URL : http://journals.openedition.org/ifha/1325 ; DOI : https:// doi.org/10.4000/ifha. 1325

Ce document a été généré automatiquement le 22 septembre 2020.

(C)IFHA 


\title{
KIEßLING, Rolf, ULLMANN, Sabine, Landjudentum im deutschen Südwesten während der Frühen Neuzeit
}

\author{
Christophe Duhamelle
}

1 Représentatif du renouvellement (dont la présente " librairie allemande » signale d'autres résultats) qu'ont connu depuis une décennie les études sur les communautés juives rurales, cet ouvrage illustre la vitalité de l'« école » qu'anime R.K. à Augsbourg mais rassemble aussi des chercheurs venus d'autres horizons. Récusant tout « révisionnisme ", ces travaux, fondés sur des études empiriques et locales, refusent néanmoins la vision sans nuance d'une histoire juive placée sous le seul signe de la persécution. Après leur expulsion, aux XVe et XVIe s., hors des villes d'Empire, les Juifs ont en effet fondé dans les campagnes du sud-ouest allemand une culture originale et des relations différenciées avec les Chrétiens. L'extrême morcellement politique de ces régions a joué un rôle majeur dans cette évolution : elle offrait d'une part la possibilité de négocier avec des autorités peu puissantes et soucieuses de s'assurer le renfort fiscal et économique apporté par les Juifs qui pouvaient jouer de la concurrence entre ces différentes instances pour trouver à se faire entendre ; mais elle exerçait également une influence sur les communautés juives, dont les différences régionales et les revendications d'autonomie s'exacerbent à mesure que leur insertion dans les institutions impériales ( " protection » assurée par l'Empereur, recours aux tribunaux impériaux) progresse et entraîne un certain mimétisme avec le fractionnement politique régional. Bien que les sources chrétiennes dominent, les douze articles prennent souvent soin de traquer les documents et les objets émanant des Juifs euxmêmes.

2 Ce thème général est ici décliné en trois sections. La première illustre la diversité croissante des cadres politiques et juridiques. La Judenordnung du Margraviat de Burgau en 1534 est déjà le fruit d'un compromis, nécessaire dans ce territorium non clausum, entre le prince, les nobles et les Juifs ; le cadre se morcellera encore, si bien que cette ordonnance de 1534 est la dernière à prétendre à une portée générale (R. 
MIX). Par la suite, la négociation prévaut, comme le montrent l'accord de 1717 entre les seigneurs von Stain et la communauté locale (S. HÖHNLE) ou encore les suppliques adressées par les Juifs au margrave de Bade-Durlach, preuves d'un échange tendu, mais réel et flexible (A. HOLENSTEIN), même si les restrictions apportées aux activités des communautés peuvent localement être extrêmement contraignantes (D.V. KOUTNÁ sur les comtes von Fugger).

3 Les autorités politiques n'ont donc pas imposé de statut unifié aux Juifs ruraux. Le deuxième volet de cet ouvrage montre qu'existent également parmi eux des évolutions et des disparités. Au sein des groupes restés en ville, les conflits entre les communautés et leurs autorités religieuses aboutissent à la fois à une resacralisation, une professionnalisation ecclésiastique et une régionalisation de l'autorité en ce domaine (D.P. BELL). Étudiant une querelle interne à la fin du XVIe s., S. ROHRBACHER montre ainsi combien les communautés souabes, suivant en quelque sorte le modèle chrétien de territorialisation, revendiquent une plus grande autonomie envers le rabbinat de Francfort-sur-le-Main. L'influence de la culture chrétienne se reflète également dans l'art sacré (K. GUTH-DREYFUS) qui permet de démentir l'image de «Juifs ruraux sans culture ", contredite également par l'existence d'une active production de livres hébraïques ouverts aux influences, en particulier iconographiques, de la culture chrétienne et de la référence aux institutions impériales (A. WEBER).

Les contacts avec les Chrétiens, auxquels est consacrée la troisième section, sont donc très variés : ces livres en hébreu sont distribués par des réseaux vastes et efficaces dans lesquels l'humanisme chrétien est partie prenante (H.-J. KÜNAST). La diversité caractérise aussi la clientèle augsbourgeoise des prêteurs sur gage juifs des environs, dont les débiteurs sont loin d'être tous misérables et leur assurent au contraire des relations solides au sein de la bourgeoisie d'Augsbourg (S. ULLMANN). À Thannhausen, seigneurie de la chevalerie d'Empire, l'inscription des Juifs dans les activités économiques, bien que soumise à un contrôle méfiant, est étroite et multiple (B. STEGMANN). La coopération - qui connaît cependant ses limites et ses regains de tension - n'est d'ailleurs pas propre au milieu rural, puisqu'on la retrouve également dans la petite ville badoise d'Emmendingen (M. SCHMÖLZ-HÄBERLEIN).

Cet ouvrage d'une belle unité offre donc un tour d'horizon bienvenu sur un terrain de recherche en plein renouvellement, et dont les interrogations ainsi que l'insistance sur les études locales et documentées rencontrent celles des travaux sur la coexistence entre les confessions chrétiennes. 